\title{
Somatostatin receptor scintigraphy in cutaneous malignant lymphomas
}

\author{
P. J. van den Anker-Lugtenburg, ${ }^{a}$ F. Heule, ${ }^{b}$ P. M. Vanhagen, ${ }^{c, d}$ Th. van Joost, ${ }^{b}$ \\ H. Y. Oei, ${ }^{\mathrm{e}}$ B. Löwenberg, ${ }^{\mathrm{a}}$ and E. P. Krenning ${ }^{\mathrm{d}, \mathrm{e}}$ Rotterdam, The Netherlands
}

\begin{abstract}
Background: Lymphoid cells may express somatostatin receptors (SS-Rs) on their cell surface. Therefore radiolabeled somatostatin analogues may be used to visualize SS-R-positive lymphoid neoplasms in vivo. Exact staging is the basis for treatment decisions in cutaneous malignant lymphoma. We considered the possibility that SS-R scintigraphy might offer a clinically useful method of diagnostic imaging in patients with cutaneous malignant lymphoma.

Objective: We evaluated SS-R scintigraphy in comparison with conventional staging methods in the staging of cutaneous malignant lymphoma.

Methods: We conducted a prospective study in 14 consecutive patients with histologically proven cutaneous malignant lymphoma. SS-R scintigraphy was compared with physical, radiologic, and bone marrow examinations. Lymph node excisions were performed in patients with palpable lymph nodes.

Results: SS-R scintigraphy was positive in the lymph nodes in all four patients with malignant lymph node infiltration and negative in the three patients with dermatopathic lymphadenopathy. In two patients, previously unsuspected lymphoma localizations were visualized by SS-R scintigraphy. In only three patients all skin lesions were visualized by SS-R scintigraphy; these three patients had not been treated with topical corticosteroids. SS-R scintigraphy failed to detect an adrenal mass in one patient and bone marrow infiltration in two patients. Conclusion: SS-R scintigraphy may help distinguish dermatopathic lymphadenopathy from malignant lymph node infiltration in patients with cutaneous malignant lymphoma.
\end{abstract}

(J Am Acad Dermatol 1996;34:985-93.)

Primary cutaneous lymphomas represent a group of non-Hodgkin's lymphomas (NHL) with involvement of the skin. Cutaneous T-cell lymphomas (CTCLs) are more common than cutaneous B-cell lymphomas (CBCLs). ${ }^{1}$ The most frequent type of CTCL is mycosis fungoides. Sézary syndrome occurs relatively rarely. CTCLs other than mycosis fungoides/Sézary syndrome represent approximately $30 \%$ of all CTCLs and are large-cell lymphomas with pleomorphic, immunoblastic, or anaplastic features. ${ }^{1}$ The malignant cell in mycosis fungoides and Sézary syndrome is a T lymphocyte, which expresses phenotypic and functional characteristics of

From the Departments of Hematology, ${ }^{a}$ Dermato-Venereology, ${ }^{b} \mathrm{Im}$ munology, ${ }^{\mathrm{c}}$ Internal Medicine III, ${ }^{\mathrm{d}}$ and Nuclear Medicine, ${ }^{\mathrm{e}}$ Erasmus University and University Hospital.

Accepted for publication Nov. 25, 1995.

Reprint requests: P. J. van den Anker-Lugtenburg, MD, Department of Hematology, University Hospital Rotterdam, Dr. Molewaterplein 40, 3015 GD Rotterdam, The Netherlands.

Copyright $\odot 1996$ by the American Academy of Dermatology, Inc. 0190-9622/96 $\$ 5.00+0 \quad \mathbf{1 6 / 1 / 7 0 8 5 2}$ helper/inducer T cells. ${ }^{2,3}$ The clinical expression of CTCL varies greatly. The disease is slowly progressive after a long initial phase and eventually may progress to involve lymph nodes, visceral organs, and peripheral blood or bone marrow. 4,5

Once the diagnosis of CTCL has been made the patient undergoes staging procedures to estimate the anatomic extent and localizations of the malignant process. The assessment of the extent is critical because the stage of disease is the most important prognostic factor in patients with CTCL and may determine the choice of therapy. ${ }^{6-10}$ The role of diagnostic imaging in the staging of CTCL is not well established. Only a few reports describe the use of imaging modalities in the staging of CTCL., $11-18$

Somatostatin is a peptide hormone consisting of 14 amino acids. It is present in the hypothalamus, the cerebral cortex, the brain stem, the gastrointestinal tract, and the pancreas. Somatostatin receptors (SSRs) have been found on normal human lymphoid tissues. ${ }^{19,}{ }^{20}$ High-affinity SS-Rs have been identified in NHLs with the use of in vitro receptor auto- 
Table I. Clinical characteristics and comparison between somatostatin receptor scintigraphy and conventional staging methods in 14 patients with cutaneous malignant lymphoma

\begin{tabular}{|c|c|c|c|c|}
\hline Patient No. & $\begin{array}{c}\text { Sex/Age } \\
\text { (yr) }\end{array}$ & Diagnosis & $\begin{array}{l}\text { Time between } \\
\text { diagnosis } \\
\text { and entry into } \\
\text { study (mo) }\end{array}$ & $\begin{array}{c}\text { Time after } \\
\text { first symptoms } \\
\text { (yr) }\end{array}$ \\
\hline 1 & $F / 67$ & CTCL: pleomorphic, medium/large & 1 & 4.0 \\
\hline 2 & $\mathrm{~F} / 84$ & CTCL: pleomorphic, small cell/medium & 1 & 0.3 \\
\hline 3 & $\mathrm{M} / 52$ & CTCL: pleomorphic, medium/large & 2 & 2.0 \\
\hline 4 & $\mathrm{M} / 58$ & CTCL: pleomorphic, medium/large, & 1 & 1.5 \\
\hline 5 & $\mathrm{~F} / 54$ & CTCL: MF & 1 & 8.0 \\
\hline 6 & $\mathrm{M} / 67$ & CTCL: MF & 1 & 7.0 \\
\hline 7 & $M / 66$ & CTCL: MF & 45 & 9.0 \\
\hline 8 & $\mathrm{~F} / 61$ & CTCL: Sézary syndrome & 1 & 5.5 \\
\hline 9 & $\mathrm{M} / 67$ & CTCL: MF & 1 & 0.8 \\
\hline 10 & $\mathrm{M} / 71$ & CTCL: MF & 1 & 20 \\
\hline 11 & $\mathrm{~F} / 58$ & CTCL: MF & 1 & 1.0 \\
\hline 12 & $\mathrm{~F} / 76$ & CBCL & 1 & 0.7 \\
\hline 13 & $M / 67$ & $\mathrm{CBCL}$ & 2 & 0.4 \\
\hline 14 & $\mathrm{~F} / 74$ & CBCL & 2 & 1.0 \\
\hline
\end{tabular}

$B M$, Bone marrow; $C B C L$, cutaneous B-cell lymphoma; $C T C L$, cutaneous T-cell lymphoma; $D L A$, dermatopathic lymphadenopathy; $F$, female; $I L C$, intralesional corticosteroid; $M$, male; $M F$, mycosis fungoides; $T C$, topical corticosteroid.

*Staging according to the Dutch Cutaneous Lymphomas Working Group (modified from Fuks). ${ }^{7,}, 12$

$\rightarrow$ Concomitant disease actinic reticuloid treated with prednisone.

†Concomitant disease dermatitis herpetiformis treated with dapsone.

radiographic techniques. ${ }^{21,22}$ On the basis of these observations, the radiolabeled somatostatin analogue $\left[{ }^{111}\right.$ In-DTPA-D-Phe $\left.{ }^{1}\right]$-octreotide has been applied clinically to visualize NHLs in vivo, with no toxicity. ${ }^{21-24}$

We describe the results of a prospective study comparing SS-R scintigraphy with conventional staging methods in 14 patients with CTCL and CBCL.

\section{PATIENTS AND METHODS}

Between 1991 and 1994, 14 consecutive patients with histologically proven CTCL $(n=11)$ and CBCL $(n=3)$ underwent staging evaluation. The stage of the disease was established by physical examination; whole body mapping of lesions; chest radiography; computed tomography (CT) of chest, abdomen, and pelvis; bone marrow aspiration and biopsy; and analysis of blood smears. CT scanning was performed with contiguous $10 \mathrm{~mm}$ axial sections after oral and intravenous administration of contrast material. Lymph node excisions were performed in patients with palpable lymph nodes.

Mycosis fungoides was staged according to a staging classification of Fuks, ${ }^{7,12}$ modified by the Dutch Cutaneous Lymphomas Working Group as follows: stage 1: skin involvement only; stage II: skin and dermatopathic lymphadenopathy; stage III: skin and pathologic lymph nodes; stage IV: skin and visceral organ involvement. Every stage was subdivided into (a) limited plaques $<10 \%$, (b) generalized plaques $>10 \%$, (c) cutaneous tumors, and (d) generalized erythroderma.

The study had been approved by the Ethics Committee of the University Hospital Rotterdam.

\section{Scintigraphy}

SS-R scintigraphy was performed after intravenous injection of the radioactive-labeled somatostatin analogue 


\begin{tabular}{|c|c|c|c|}
\hline $\begin{array}{l}\text { Previous } \\
\text { treatment }\end{array}$ & Stage* & $\begin{array}{l}\text { Disease sites by } \\
\text { conventional methods }\end{array}$ & $\begin{array}{l}\text { Disease sites by } \\
\text { SS-R scintigraphy }\end{array}$ \\
\hline \multicolumn{2}{|l|}{$\mathrm{TC}$} & Skin: macules on total skin and urticaria & Skin negative \\
\hline \multicolumn{2}{|l|}{ None } & Skin: ulcers and plaques, erythema on legs & Skin negative \\
\hline \multicolumn{2}{|l|}{ PUVA } & Skin: limited plaques & Skin positive (only arm) \\
\hline \multicolumn{2}{|l|}{$\mathrm{TC}$} & DLA (axilla, inguinal) & DLA negative \\
\hline \multirow{2}{*}{\multicolumn{2}{|c|}{$\mathrm{TC}$}} & Skin: erythroderma & Skin negative \\
\hline & & Lymph nodes (axilla, inguinal) & Lymph nodes positive \\
\hline $\mathrm{TC}$ & Ia & Skin: plaques & Skin negative \\
\hline $\mathrm{TC}$ & $\mathrm{Ib}$ & Skin: plaques & Skin negative \\
\hline $\mathrm{TC}$ & $\mathrm{IVb}$ & Skin: ulcers and plaques & Skin negative \\
\hline \multicolumn{2}{|l|}{ UVB } & DLA (neck, axilla, inguinal) & $\begin{array}{l}\text { DLA negative } \\
\text { Synovia positive }\end{array}$ \\
\hline \multirow[t]{3}{*}{$\mathrm{TC}$} & & Skin: erythroderma & Skin negative \\
\hline & & Lymph nodes (inguinal) & Lymph nodes positive \\
\hline & & $\mathrm{BM}$ & BM negative \\
\hline \multirow[t]{3}{*}{ None } & IVc & Skin: tumors & Skin positive \\
\hline & & Lymph nodes (inguinal) & Lymph nodes positive \\
\hline & & Adrenal region & Adrenal region negative \\
\hline \multirow[t]{2}{*}{$\mathrm{TC}+$} & ПId & Skin: erythroderma & Skin negative \\
\hline & & DLA (axilla, inguinal) & DLA negative \\
\hline $\mathrm{TC}$ & $\mathrm{Ib}$ & Skin: macules & Skin negative \\
\hline \multirow{2}{*}{\multicolumn{2}{|c|}{ None }} & Skin: ulcers on leg and hips & Skin positive \\
\hline & & & Mediastinum positive \\
\hline \multicolumn{2}{|l|}{ None $\$$} & Skin: nodule on neck & Skin positive \\
\hline \multicolumn{2}{|l|}{$\mathrm{TC}, \mathrm{ILC}$} & Skin: plaques around eye & Skin negative \\
\hline
\end{tabular}

[ ${ }^{111}$ In-DTPA-D-Phe ${ }^{1}$-octreotide] (Mallinckrodt Medical BV, Petten, The Netherlands). The preparation of [ ${ }^{111} \mathrm{In}-$ D'TPA-D-Phe ${ }^{1}$-octreotide, the dose administered $(\geq 200$ $\mathrm{MBq}$ ), and the technique of scintigraphy with the gamma camera, as well as with single photon emission computed tomography (SPECT) have recently been described. ${ }^{23,25}$ Planar total body scintigraphy was performed 24 hours after injection with a large-field-of-view gamma camera (Counterbalance 3700 and ROTA II; Siemens Gammasonics, Erlangen, Germany) equipped with a medium-energy collimator. Repeat scintigrams were performed 48 hours after injection when accumulation of radioactivity in the abdomen was observed on the 24-hour scintigrams. In all patients SPECT images of the upper abdomen were made. In normal persons a physiologic accumulation of radioactivity may be seen in the pituitary and thyroid glands, liver, spleen, kidneys, urinary bladder, and occasionally in the gallbladder. The presence of intestinal radioactivity (mainly in the colon at 24 hours) is caused by some hepatobiliary clearance of $\left[{ }^{111}\right.$ In-DTPA-D-Phe $\left.{ }^{1}\right]$-octreotide and can be reduced by the use of laxatives. ${ }^{25,26}$ The scans were evaluated by two investigators (E. P. K. and H. Y.
O.) who did not know the identity of the patients or the results of the conventional staging procedures. Finally the results of SS-R scintigraphy and conventional diagnostic tests were compared by the study coordinator ( $\mathrm{P}$. J. v.d.A.). In case of discrepancies additional radiodiagnostic investigations were scheduled, and if practical and possible, histologic verification was attempted. All patients were observed during and after treatment. In three patients SS-R scintigraphy was repeated during followup.

\section{RESULTS}

The clinical characteristics of the 14 patients with CTCL $(n=11)$ and CBCL $(n=3)$ in whom SS-R scintigraphy was performed are given in Table I. Ten of 14 patients had been treated for long periods with topical corticosteroids.

\section{Patients with CTCL}

SS-R scintigraphy was positive in 5 of 11 patients with CTCL. The results of the comparison between the sites of disease demonstrated by SS-R scintigra- 
Table II. Results of physical examination, CT scan, and SS-R scintigraphy in relation with lymph node histologic findings in 14 patients with cutaneous malignant lymphoma

\begin{tabular}{c|l|l|l|l}
\hline Patient No. & $\begin{array}{c}\text { Plysical examination } \\
\text { lymph node } \\
\text { diameter (cm) }\end{array}$ & $\begin{array}{c}\text { CT scan } \\
\text { lymph node } \\
\text { diameter (cm) }\end{array}$ & $\begin{array}{c}\text { 仵-R scintigraphy } \\
\text { lymph node areas }\end{array}$ & $\begin{array}{c}\text { Lymph node } \\
\text { histologic findings }\end{array}$ \\
\hline 1 & 3 & 3 & Positive* & Malignant infiltration \\
2 & Negative & Negative & Negative & ND \\
3 & 1.5 & 2 & Negative & Dermatopathic lymphadenopathy \\
4 & $2-3$ & $2-3$ & Positive & Malignant infiltration \\
5 & Negative & Negative & Negative & ND \\
6 & Negative & ND & Negative & ND \\
7 & 2 & $1.5-2$ & Negative & Dermatopathic lymphadenopathy \\
8 & $2-4$ & $2-4$ & Positive & Malignant infiltration \\
9 & 2 & 1.8 & Positive & Malignant infiltration \\
10 & 3 & 3 & Negative & Dermatopathic lymphadenopathy \\
11 & Negative & Negative & Negative & ND \\
12 & Negative & Negative & Negative & ND \\
13 & Negative & Negative & Negative & ND \\
14 & Negative & Negative & Negative & ND \\
\hline
\end{tabular}

$C T$, Computed tomography; $N D$, not done; $S S-R$, somatostatin receptor.

*Result of SS-R scan during follow-up.

phy and the conventional staging methods are summarized in Table I.

\section{Skin evaluation}

CTCL was limited to the skin in 6 of 11 patients. In five of these six patients (i.e., two patients with pleomorphic CTCL [patients 1 and 2] and three patients with mycosis fungoides [patients 5,6, and 11]), SS-R scintigraphy was negative. The skin lesions in these patients were macules or plaques. Patient 3 initially had limited plaques of 0.5 to $10 \mathrm{~cm}$ diameter on multiple sites of the skin. Only one of these lesions was visualized on SS-R scintigraphy.

Five of 11 patients had CTCL in a more advanced stage. In only one of these patients were the skin lesions shown by SS-R scintigraphy. This patient (No. 9) had multiple, sharply marginated, erythematous tumors on the skin of the face and back (Fig. 1).

\section{Lymph node evaluation}

The results of physical examination, CT scanning, and SS-R scintigraphy in relation to lymph node histology are summarized in Table II. In six patients, diseased lymph nodes of 1.5 to $3 \mathrm{~cm}$ in diameter were palpable at physical examination. Five of these patients had generalized lymphadenopathy. These enlarged lymph nodes were all apparent on CT scan. In three patients SS-R scintigraphy was negative in the lymph node areas (patients 3, 7, and 10). Lymph node excisional biopsy specimens in these three pa- tients showed dermatopathic lymphadenopathy. SS-R scintigraphy was positive in the lymph node areas in the other three patients (patients 4, 8, and 9; Fig. 2). The lymph node excisional biopsy specimens in these three patients confirmed the involvement of malignant lymphoma. The sensitivity and specificity of the CT scan for malignant lymph node infiltration were $100 \%$ and $67 \%$, respectively. The sensitivity and specificity of SS-R scintigraphy for malignant lymph node infiltration were $100 \%$ and $100 \%$, respectively.

In the 14 patients no lymphadenopathy in the thorax or abdomen was seen on CT scans of chest, abdomen, and pelvis or by SS-R scintigraphy.

\section{Organ evaluation}

Dissemination of CTCL to visceral organs or bone marrow was seen in three patients. Patient 7 had a seronegative arthropathy affecting the hands and wrists. SS-R scintigraphy was positive in multiple joints (hands, wrists, elbows, knees, and ankles). A synovial biopsy specimen showed an infiltrate of lymphocytes (exclusively $\mathrm{T}$ lymphocytes) and plasma cells in a reactive pattern. T-cell receptor gene rearrangement analysis was performed on skin and synovial specimens, and identical clonal T-cell populations were detected in both (data not shown). Bone marrow infiltration with Sézary cells (15\%) was seen in patient 8 but was not apparent on SS-R 


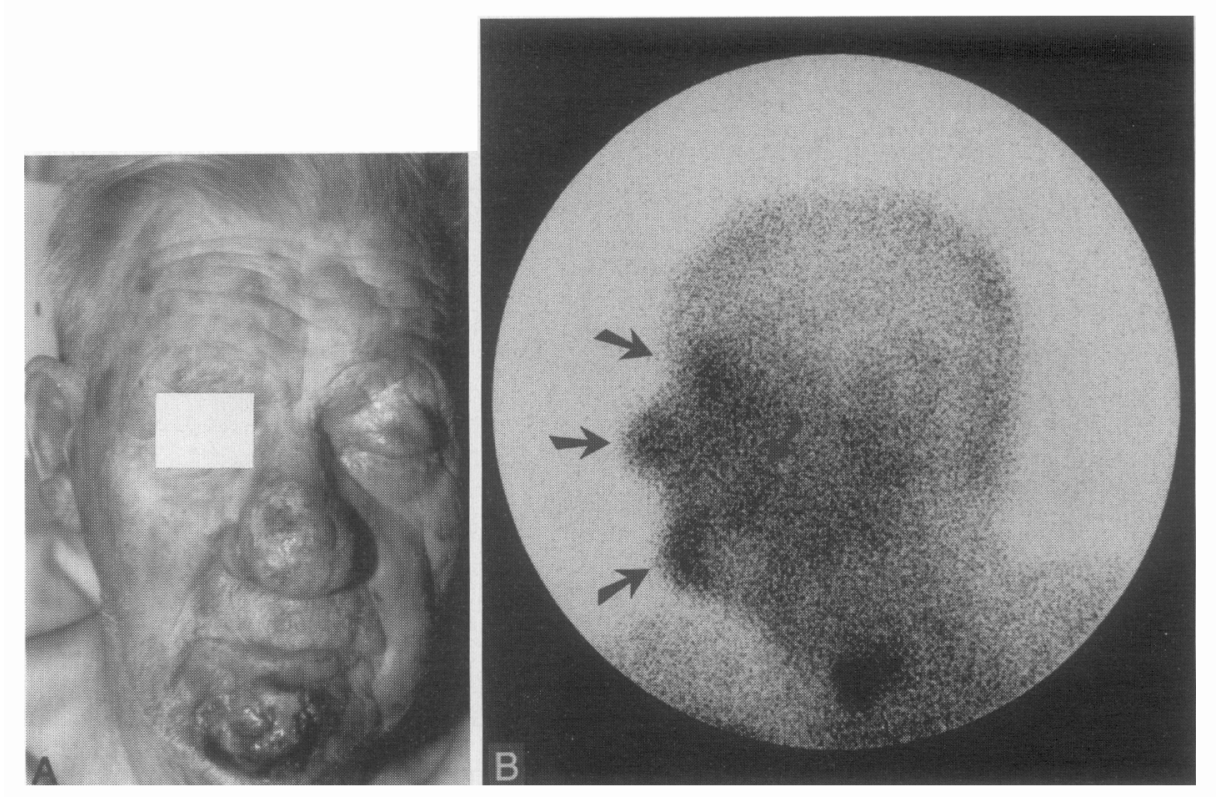

Fig. 1. A, Patient with mycosis fungoides, multiple tumors on face. B, Same patient, left lateral planar view of head and neck. Normal accumulation of radioactivity in the thyroid. Skin tumors clearly visualized (arrows).

scintigraphy. CT scanning demonstrated a large adrenal mass $(5$ to $7 \mathrm{~cm})$ in patient 9 . Cytologic examination of a needle aspiration specimen of the adrenal mass confirmed infiltration with CTCL. SS-R scintigraphy was negative in this area.

\section{SS-R scintigraphy during follow-up}

In three patients with pleomorphic CTCL, SS-R scintigraphy was repeated during follow-up. Patient 1 , with initially negative SS-R scanning, was treated with PUVA therapy. Sixteen months later progressive skin disease had developed as well as lymph node and bone marrow infiltration with CTCL. SS-R scintigraphy was positive in the peripheral lymph node areas, but remained negative in the skin and bone marrow. In patient 2 a complete remission was reached after CHOP chemotherapy. Eleven months later the skin disease recurred (ulcers and plaques). SS-R scintigraphy was again entirely negative. The skin disease in patient 3 , originally showing positivity on SS-R scintigraphy, recurred (tumors at multiple sites) 8 months after PUVA therapy and local radiotherapy. On SS-R scintigraphy some skin lesions were positive and some were negative. The patient did not respond to different types of chemotherapy and local radiotherapy. SS-R scintigraphy performed a third time revealed all active skin lesions (tumors).

\section{Patients with $\mathrm{CBCL}$}

SS-R scintigraphy was positive in two of three patients with CBCL (Table I). The skin lesions were visualized by SS-R scintigraphy in two patients. In patient 12 , SS-R scintigraphy also revealed a previously unsuspected localization in the mediastinum (Fig. 3, A). On roentgenography and CT of the tho$\operatorname{rax}$ (Fig. 3, B) no abnormalities were seen. However, this patient had radiologic evidence of mediastinal lymphoma 6 months later. Mediastinal lymphoma involvement with pericardial infiltration was confirmed at autopsy. In patient 13 the accumulation of radioactivity in the neck corresponded to a clinically evident skin nodule $(2 \mathrm{~cm})$ in the neck. SS-R scintigraphy was entirely negative in the third patient.

Side effects were not noted in any of the patients after the administration of [ ${ }^{111}$ In-DTPA-D-Phe ${ }^{1}$ octreotide for SS-R scintigraphy.

\section{DISCUSSION}

The prognosis and treatment of patients with CTCL depend on accurate staging. The staging system for CTCL considers the extent of skin involvement, presence of lymph node or visceral disease, and detection of abnormal cells in the peripheral blood. In autopsy series, more than $70 \%$ of patients 

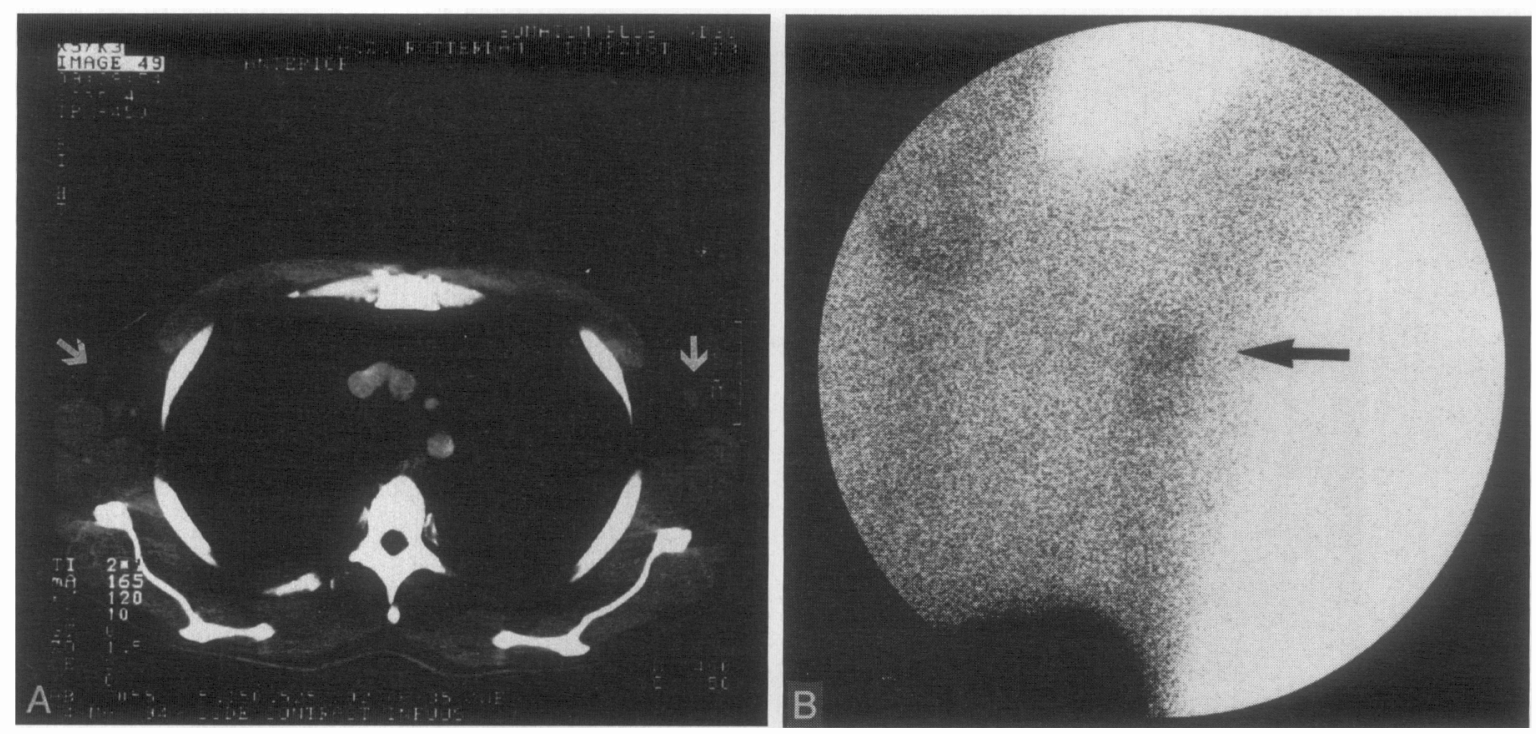

Fig. 2. A,CT scan of the thorax of patient with pleomorphic CTCL shows multiple enlarged lymph nodes ( 1.5 to $2 \mathrm{~cm}$ in diameter) in the axillary regions (arrows). Lymph node excision biopsy specimen showed malignant lymphoma infiltration. B, Same patient, anterior planar thoracic image. Normal accumulation of radioactivity in the thyroid and spleen; abnormal accumulation in the axilla (arrow).

with CTCL have extracutaneous lesions that may involve nearly any organ. ${ }^{6,27,28}$ Despite the high incidence of extracutaneous CTCL found at autopsy, clinically overt extracutaneous disease, other than that involving peripheral lymph nodes and blood, is uncommon.

In the present study, we employed SS-R scintigraphy in 11 patients with histologically proven CTCL and three patients with CBCL. Among these, eight showed a positive SS-R scan. SS-R-positive localizations were apparent at different sites of active disease in the skin and in extracutaneous disease.

Extracutaneous disease in CTCL is frequently found in lymph nodes. Histologic interpretation of lymph nodes in CTCL is sometimes difficult. Unlike the nodes in B-cell lymphomas, most often the nodal architecture is preserved and lymph nodes are rarely totally replaced by malignant $\mathrm{T}$ cells. Furthermore, patients with CTCL frequently have benign reactive lymphadenopathy or dermatopathic lymphadenopathy. In dermatopathic lymphadenopathy the paracortical T-cell zones may contain focal accumulations of atypical convoluted T lymphocytes. Southern blot analysis of the T-cell receptor gene has provided evidence of CTCL infiltration in dermatopathic lymph nodes. ${ }^{29,30}$ Patients with malignant lymph nodes tend to have a shorter survival than pa- tients with dermatopathic lymphadenopathy. ${ }^{9,31}$ If malignant lymph node infiltration is apparent, patients are usually treated with systemic chemotherapy. This is in contrast to patients with dermatopathic lymphadenopathy to whom chemotherapy is less commonly given. Therefore it is common practice to perform lymph node excisions in patients with CTCL and peripheral enlarged lymph nodes. In our study seven patients initially had or later developed enlarged palpable axillary or inguinal lymph nodes. SS-R scintigraphy was positive in all four of these seven patients with malignant lymph node infiltration. All infiltrated lymph nodes were visualized by SS-R scintigraphy. The lymph node areas were negative on SS-R scintigraphy in the three patients with dermatopathic lymphadenopathy. CT does not allow differentiation between enlarged peripheral lymph nodes with histologic evidence of CTCL and nodes demonstrating dermatopathic lymphadenopathy. Although our series of patients is small, the results would suggest that in contrast to other imaging modalities SS-R scintigraphy may differentiate between malignant lymph node infiltration and dermatopathic lymphadenopathy in patients with CTCL. In patients with enlarged lymph nodes, a surgical lymph node excision might perhaps be avoided on the basis of SS-R scintigraphy results. 

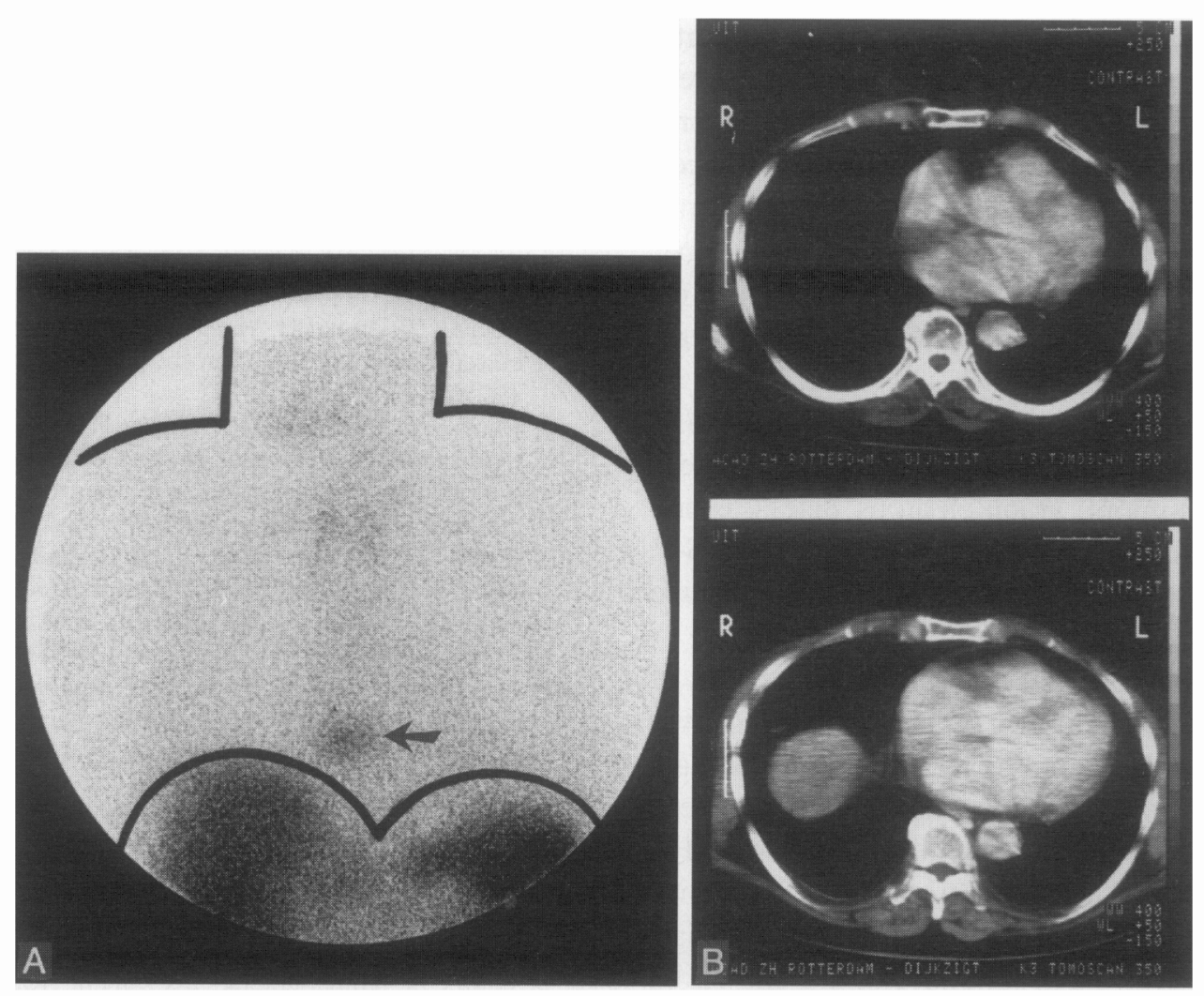

Fig. 3. A, Anterior thoracic planar image in patient with CBCL revealed previously unsuspected lymphoma in mediastinum (arrow). Normal uptake of labeled octreotide is seen in the thyroid, liver, spleen. B, Same patient, CT scan of the thorax, no abnormalities were seen.

Another possible advantage of SS-R scintigraphy is that the whole body is imaged, so that localizations not under clinical suspicion can be evaluated. In two patients, previously unsuspected lymphoma localizations were revealed by SS-R scintigraphy, that is, in the mediastinum and multiple joints. Although in patient 7 only reactive $T$ lymphocytes were seen in the synovial specimen, clonality of these $T$ lymphocytes was demonstrated by T-cell receptor gene rearrangement analysis. By analogy with the demonstration of clonal T-cell lymphocytic infiltration in dermatopathic lymphadenopathy, ${ }^{29,}{ }^{20}$ the presence of clonal $\mathrm{T}$ lymphocytes alone in the synovia, although not sufficient for the diagnosis of malignant infiltration with CTCL, is highly suggestive of the (pre)malignant character of the infiltrate.

On the other hand, SS-R scintigraphy failed to detect an adrenal mass and bone marrow infiltration. The adrenal mass may not have been detected by SS-R scintigraphy because of the physiologic uptake of the radioligand in the kidneys. This might have interfered with the detection of adrenal involvement, despite the use of SPECT. The reason that bone marrow infiltration was not revealed by SS-R scintigraphy is unclear. A locally low density of receptors and unknown local factors may be involved.

At first sight, SS-R scintigraphy appears of minor value in the confirmation of early skin disease in CTCL. The skin lesions were visualized in only two patients. In both patients the skin disease was in the tumor stage. Skin tumors usually develop at later stages. Only one of several plaques was detected by SS-R scintigraphy in patient 3 . This skin lesion was the presenting lesion several years before mycosis fungoides was diagnosed. In the other patients no accumulation of radioactivity was seen in the plaques. We can only speculate as to the reason SS-R scintigraphy failed to visualize these thin lesions. One explanation might be that most of the patients had been treated for long periods with topical corticosteroids. Except for patient 3 in whom only one of several lesions was visualized by SS-R scintigraphy, none of the three other patients in whom the skin lesions were visualized had been treated with topical 
corticosteroids. The topical administration of corticosteroids might have influenced the SS-R expression on the tumor cells. Long-term exposure of rat pituitary tumor cells to glucocorticoids has been demonstrated to result in downregulation of somatostatin binding because of a decrease in the number of SS-Rs per cell. ${ }^{32}$ Dexamethasone treatment reduced the number of SS-Rs 2.5-fold in a rat pancreatic carcinoma cell line. ${ }^{33}$

SS-R scintigraphy is not specific for visualizing tissues infiltrated with malignant lymphomas. Neuroendocrine tumors, granulomatous diseases, and autoimmune diseases may be visualized by SS-R scintigraphy as well. ${ }^{23}$ However, no false-positive results were seen in this study.

SS-R scintigraphy not only indicates the sites of involvement of a malignant process, but it also gives information on the expression of SS-Rs. Modest activity of somatostatin as a single agent has been demonstrated by Witzig et al. ${ }^{34}$ in low-grade NHL and CTCL. SS-R scintigraphy was not performed before or after treatment. It is tempting to postulate that patients who have tumors that are shown by SS-R scintigraphy will be most likely to respond to therapy with somatostatin or to radiotherapy with a somatostatin analogue coupled to a $\beta$-emitting radionuclide.

SS-R scintigraphy appears to provide an independent approach to the evaluation of dissemination of CTCL and CBCL. Although further studies are necessary in a larger group of patients before definite conclusions can be made, our results suggest that SS-R scintigraphy may be able to distinguish dermatopathic lymphadenopathy from malignant lymph node infiltration in certain patients with CTCL and be useful in a complete staging work-up of patients with cutaneous malignant lymphomas.

\section{REFERENCES}

1. Willemze R, Beljaards RC, Meijer CJLM. Classification of primary cutaneous T-cell lymphomas. Histopathology 1994;24:405-15.

2. Broder S, Edelson RL, Lutzner MA, et al. The Sézary syndrome:a malignant proliferation of helper $\mathrm{T}$ cells. J Clin Invest 1976;58:1297-306.

3. Kung PC, Berger CL, Goldstein G, et al. Cutaneous T cell lymphoma: characterization by monoclonal antibodies. Blood 1981:57:261-6.

4. Bunn PA, Poiesz BJ. Cutaneous T-cell lymphomas (mycosis fungoides and Sézary syndrome). In: Williams WJ, Beutler E, Erslev AJ, et al, editors. Hematology. New York: McGraw-Hill, 1983:1056-66.

5. Edelson RL. Cutaneous T cell lymphoma: mycosis fun- goides, Sézary syndrome, and other variants. J Am Acad Dermatol 1980;2:89-106.

6. Epstein EH, Levin DL, Croft JD Jr, et al. Mycosis fungoides: survival, prognostic features, response to therapy and autopsy findings. Medicine (Baltimore) 1972; 51:61-72.

7. Fuks ZY, Bagshaw MA, Farber EM. Prognostic signs and the management of the mycosis fungoides. Cancer 1973; 32:1385-95.

8. Levi JA, Wiernik PH. Management of mycosis fungoides, current status and future prospects. Medicine (Baltimore) 1975;54:73-8.

9. Bunn PA, Huberman MS, Whang-Peng J, et al. Prospective staging evaluation of patients with cutaneous T-cell lymphomas: demonstration of a high frequency of extracutaneous dissemination. Ann Intern Med 1980;93:223-30.

10. Green SB, Byar DP, Lamberg SI. Prognostic variables in mycosis fungoides. Cancer 1981;47:2671-7.

11. Fuks ZY, Castelino RA, Carmel JA, et al. Lymphography in mycosis fungoides. Cancer 1974;34:106-12.

12. Hamminga L, Mulder JD, Evans C. Staging lymphography with respect to lymph node histology, treatment, and follow-up in patients with mycosis fungoides. Cancer 1981; 47:692-7.

13. Rosen ST, Gore R, Brennan J, et al. Evaluation of computed tomography and radionuclide scanning in the staging of cutaneous T-cell lymphoma. Arch Dermatol 1986;122:884-6.

14. Escovitz ES, Soulen RL, Van Scott EJ, et al. Mycosis fungoides: a lymphographic assessment. Radiology 1974; 112:23-7.

15. Shaperoo LG, Young SW. Mycosis fungoides: manifestations on computed tomography. Radiology 1983;148:202.

16. Kulin PA, Marglin SI, Shuman WP, et al. Diagnostic imaging in the initial staging of mycosis fungoides and Sézary syndrome. Arch Dermatol 1990;126:914-8.

17. Miketic LM, Chambers TP, Lembersky BC. Cutaneous Tcell lymphoma: value of CT in staging and determining prognosis. Am J Roentgenol 1993;160:1129-32.

18. Bass JC, Korobkin MT, Cooper KD, et al. Cutaneous Tcell lymphoma: CT in evaluation and staging. Radiology 1993;186:273-8.

19. Reubi JC, Waser B, Horisberger U, et al. In vitro autoradiographic and in vivo scintigraphic localization of somatostatin receptors in human lymphatic tissue. Blood 1993; 82:2143-51

20. Reubi JC, Horisberger U, Waser B, et al. Preferential location of somatostatin receptors in germinal centers of human gut lymphoid tissue. Gastroenterology 1992;103:1207-14.

21. Reubi JC, Waser B, Van Hagen PM, et al. In vitro and in vivo detection of somatostatin receptors in human malignant lymphomas. Int J Cancer 1992;50:895-900.

22. Van Hagen PM, Krenning EP, Reubi JC, et al. Somatostatin analogue scintigraphy of malignant lymphomas. $\mathrm{Br} \mathrm{J}$ Haematol 1993;83:75-9.

23. Krenning EP, Kwekkeboom DJ, Bakker WH, et al. Somatostatin receptor scintigraphy with [ ${ }^{111}$ In-DTPA-D-Phe ${ }^{1}$ and $\left.{ }^{123} \mathrm{I}-\mathrm{Tyr}^{3}\right]$-octreotide: the Rotterdam experience with more than 1000 patients. Eur J Nucl Med 1993;20:716-31.

24. Lipp RW, Silly H, Ranner G, et al. Radiolabeled octreotide for the demonstration of somatostatin receptors in malignant lymphoma and lymphadenopathy. J Nucl Med 1994; 36:13-8.

25. Krenning EP, Bakker WH, Kooij PPM, et al. Somatostatin receptor scintigraphy with Indium-111-DTPA-D-Phe-1- 
octreotide in man: metabolism, dosimetry, and comparison with Iodine-123-Tyr-3-octreotide. J Nucl Med 1992;33: 652-8.

26. Bakker WH, Albert R, Bruns C, et al. [111 In-DTPA-D$\mathrm{Phe}^{1}$ ]-octreotide, a potential radiopharmaceutical for imaging of somatostatin receptor positive tumors: radiolabeling and in vitro validation. Life Sci 1991;49:1583-91.

27. Rappaport H, Thomas LB. Mycosis fungoides: the pathology of extracutaneous involvement. Cancer 1974;34:1198229.

28. Long JC, Mihm M. Mycosis fungoides with extracutaneous dissemination: a clinical pathologic entity. Cancer 1974;34:1745-55.

29. Weiss LM, Hu E, Wood GS, et al. Clonal rearrangements of T-cell receptor genes in mycosis fungoides and dermatopathic adenopathy. N Eng1 J Med 1985;313:539-44.
30. Whittaker SJ, Smith NP, Jones RR, et al. Analysis of $\beta, \gamma$, and $\delta \mathrm{T}$-cell receptor genes in mycosis fungoides and Sézary syndrome. Cancer 1991;68:1572-82.

31. Scheffer G, Meijer CJLM, van Vloten WA. Dermatopathic lymphadenopathy and lymph node involvement in mycosis fungoides. Cancer 1980;45:137-48.

32. Schonbrunn A. Glucocorticoids down-regulate somatostatin receptors on pituitary cells in culture. Endocrinology 1982;110:1147-54.

33. Viguerie N, Estève JP, Susini C. Dexamethasone effects on somatostatin receptors in pancreatic acinar AR4-2J cells. Biochem Biophys Res Commun 1987;147:942-8.

34. Witzig TE, Letendre L, Gerstner J, et al. Evaluation of a somatostatin analog in the treatment of lymphoproliferative disorders: results of a phase II North Central Cancer Treatment Group Trial. J Clin Oncol 1995;13:2012-15.

\section{ON THE MOVE? \\ Send us your new address at least six weeks ahead}

Don't miss a single issue of the journal! To ensure prompt service when you change your address, please photocopy and complete the form below.

Please send your change of address notification at least six weeks before your move to ensure continued service. We regret we cannot guarantee replacement of issues missed due to late notification.

JOURNAL TITLE:

Fill in the title of the journal here.

OLD ADDRESS:

Affix the address label from a recent issue of the journal here.

\section{NEW ADDRESS:}

Clearly print your new address here.

Name

Address

City/State/ZIP

\section{COPY AND MAIL THIS FORM TO:}

Journal Subscription Services Mosby-Year Book, Inc.

11830 Westline Industrial Dr.

St. Louis, MO 63146-3318

\section{OR FAX TO:}

314-432-1158

N/Mosby
OR PHONE:

1-800-453-4351

Outside the U.S., call

314-453-4351 